\title{
Produtos culturais e redes sociais na sala de aula
}

\author{
José Ribamar Lopes Batista Júnior*
}

Resumo: Neste trabalho, relatamos uma experiência de uso de mídias digitais no ensino de língua materna com alunos do ensino médio profissionalizante do Colégio Agrícola de Floriano/ UFPI. O projeto teve por objetivo desenvolver práticas de leitura e escrita dos alunos a partir da utilização de produtos culturais (CD, DVD, filme e livro) e de redes sociais (blog, Twitter, Youtube, Flicker) como espaços de acesso e produção de diversos gêneros textuais e digitais. $\mathrm{O}$ projeto consistiu na integração dessas mídias digitais como recurso pedagógico no ensino de língua portuguesa, compreendendo os seguintes procedimentos: i) levantamento e escolha dos produtos culturais; ii) exibição/ leitura dos produtos; iii) elaboração, correção e reescritura de textos; e iv) produção e apresentação de vídeos sobre os produtos. Assim, o significativo interesse e motivação dos alunos revelaram as possibilidades/potencialidades do uso das mídias digitais no processo ensino-aprendizagem, especialmente a internet e suas ferramentas, instrumentos cada vez mais presentes no cotidiano dos estudantes.

Palavras-chave: Produtos Culturais; Redes Sociais; Leitura e Escrita.

Abstract: In this paper, we report an experience of using digital media in teaching Portuguese language vocational high school students of the Colégio Agrícola de Floriano/UFPI. The project aimed to develop reading and writing practices of students from the use of cultural products (CD, DVD, movie and book) and social networking (blog, Twitter, YouTube, Flicker) as areas of

Professor da Universidade Federal do Piauí (UFPI). Doutorando e Mestre em Linguística pela Universidade de Brasília (UnB). E-mail: ribasninja@gmail.com 
access and production of various text genres and digital. The project involved the integration of digital media as an educational resource in the teaching of Portuguese, comprising the following: i) survey and selection of cultural products; ii) viewing/ reading products, iii) the preparation, correction and rewriting of texts, and iv) production and presentation of videos about the products. Thus, the significant interest and motivation of the students revealed the possibilities/potential use of digital media in teaching-learning process, especially the Internet and its tools, instruments increasingly present in daily life of students.

Keywords: Cultural Products; Social Networks; Reading and Writing.

\section{Introdução}

A partir de atividades realizadas em sala de aula, constatamos um distanciamento dos alunos em relação à leitura e à escrita escolar (BATISTA JR et al., 2010; BATISTA JR E SILVA, 2010; BATISTA JR, SILVA E LIRA, 2011). Diante disso, criamos o projeto Pipoca Cultural com o objetivo maior de desenvolver práticas de letramento (práticas de leitura e escrita) a partir do uso de produtos culturais (CD, DVD, filme e livro) em sala de aula. O projeto justifica-se pelo grande e espontâneo interesse dos jovens pelos produtos culturais e, principalmente, pelas redes sociais (blog, Twitter, YouTube, Flicker), considerando que eles passam muito tempo assistindo a filmes e seriados, ouvindo músicas, lendo livros temáticos (trilogias, séries etc.) e, a maioria, navegando nas redes sociais (XAVIER, 2011). Com isso, acreditamos que também seria possível trabalhar vários aspectos do ensino de língua portuguesa, entre eles as técnicas do resumo, a argumentação, a crítica, a expressão verbal e corporal, a produção e mobilização de variados saberes que em última análise favorecem a qualificação das práticas de leitura e escrita dos alunos. Além disso, essa atividade proporcionaria a 
revitalização/qualificação da prática docente no ensino da língua materna (portuguesa) no Colégio Agrícola de Floriano.

No presente trabalho, relataremos essas experiências, explicitando os procedimentos metodológicos do projeto, com descrição de cada etapa do processo de realização do mesmo e, dessa forma, refletiremos sobre o uso dos gêneros textuais digitais e, principalmente, das redes sociais como ferramentas para o desenvolvimento da leitura e da escrita na Educação Profissional.

\section{Objetivos}

O projeto tem como objetivo desenvolver nos alunos práticas de leitura e escrita, a partir da utilização de produtos culturais (CD, DVD, filme e livro) e de redes sociais (blog, Twitter, YouTube), como espaços de acesso e produção de diversos gêneros textuais e digitais (sinopses, fichas técnicas, resenhas, trailers, propagandas, posts, tweets, vídeos etc.).

\section{Metodologia}

O projeto foi realizado com alunos/as de uma escola de ensino médio profissionalizante da rede federal localizada no município de Floriano/PI, no período de abril a junho de 2011. A proposta compôs um conjunto de atividades avaliativas da disciplina de Língua Portuguesa ministrada por mim e contou com a participação de 160 alunos/as dos $1^{\circ}$ e $2^{\circ}$ anos dos cursos técnicos de Agropecuária, Enfermagem e Informática.

A metodologia adotada compreendeu o levantamento e a escolha dos produtos culturais; sua exibição/leitura; elaboração, correção e reescritura de sinopses e de fichas técnicas; criação e realização de enquetes, por meio da internet, sobre a recepção dos produtos; produção e apresentação de vídeos e elaboração de resenhas. 
Assim, o corpus deste trabalho resultou dos registros de observações das atividades dos/as alunos/as nas diferentes etapas do processo de desenvolvimento do projeto, sobre os quais realizamos o presente relato.

\section{Projeto Pipoca Cultural}

$\mathrm{O}$ projeto iniciou-se em abril com a apresentação da proposta, dos objetivos e da finalidade à Coordenação-Geral de Ensino e da intenção de utilizá-lo como avaliação da disciplina de Língua Portuguesa. Nessa etapa houve um estranhamento em razão da concepção de Ensino de Língua voltada para a Gramática tradicional (SILVA, 2008), bem como para o uso de provas escritas conservadoras. Em razão disso, foi importante o trabalho de convencimento reflexivo no sentido de demonstrar que Língua Portuguesa se vivencia por meio de usos situados, nos quais os textos emergem com finalidade de promover a interação (BARTON, 2006; 2009), e que o domínio desses usos promove o empoderamento dos atores sociais.

O público alvo seriam os/as alunos/as de quatro turmas de ensino médio profissionalizante, matutino e vespertino, na faixa etária de 14 a 16 anos, em sua maioria. Inicialmente os/as alunos/as foram informados de que seriam utilizados diferentes produtos culturais durante as aulas, sem que fosse mencionada a produção textual que deveriam realizar após a exploração dos mesmos. Com os discentes, definimos que cada sala elegeria dois filmes, dois livros, um CD e um DVD (seriado ou show), lançados em 2010 ou no primeiro semestre de 2011. Em seguida, dividimos as turmas em grupos de seis pessoas, sendo seis produtos para cada sala.

Depois da formação dos grupos, fizemos um sorteio a fim de distribuir os tipos de produtos. Os grupos teriam o prazo de uma semana para apresentar os títulos de seus produtos, informando para mim e para os demais colegas a escolha referente ao livro, filme, CD ou DVD selecionados. Diante disso, todos 
tiveram até $1^{\circ}$ de maio (nesse caso, um mês) para explorar o material selecionado (ler, assistir e/ou ouvir), para em seguida desenvolvermos o estudo e a produção do gênero sinopse.

Enquanto os alunos desenvolviam as respectivas leituras, criamos um blog ${ }^{1}$, um canal no YouTube e no Flickr ${ }^{3}$, um perfil no Twitter ${ }^{4}$ com o intuito de divulgar posteriormente todos os trabalhos.

Figura 1: Blog Pipoca Cultural

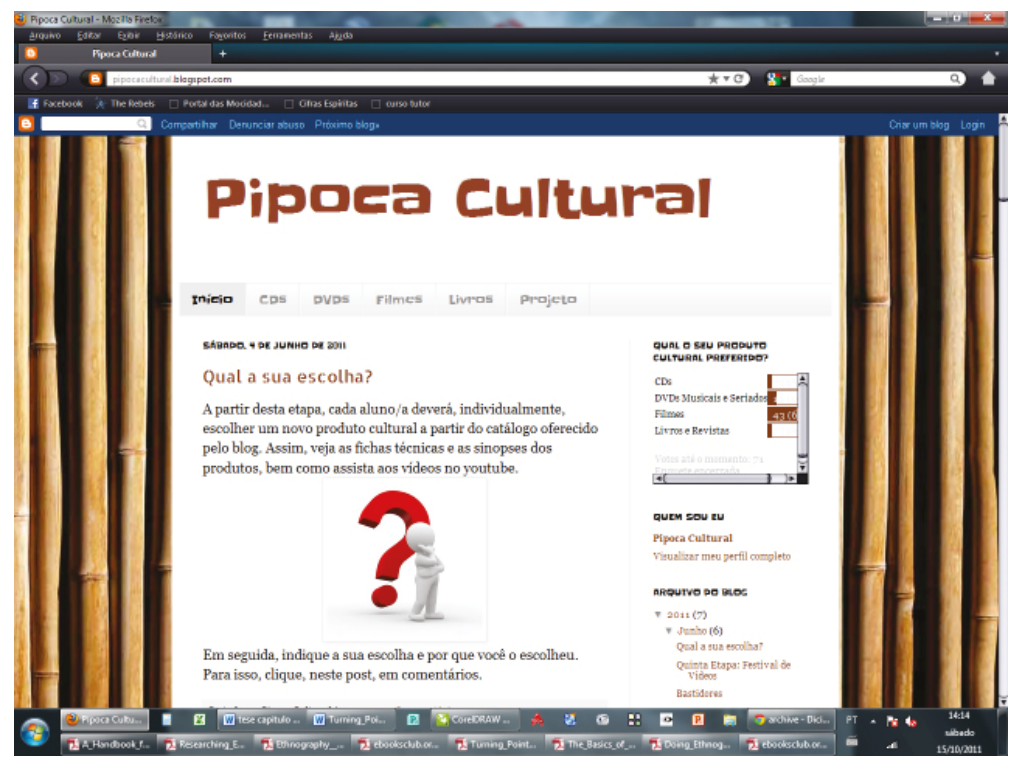

No blog trabalhamos o gênero enquete, mediada por computador. Na comunicação digital o gênero é frequente, sendo

Disponível em: < http://pipocacultural.blogspot.com/>. Acesso em: 11 set. 2011.

2 Disponível em: < http://www.youtube.com/user/PipocaCultural >. Acesso em: 11 set. 2011.

3 Disponível em: <http://www.flickr.com/photos/pipocacultural/sets/72157626761162589/>. Acesso em: 11 set. 2011.

4 Disponível em: < http://twitter.com/\#!/pipocacultural>. Acesso em: 11 set. 2011. 
uma forma de interação na internet. Em nosso blog, estabelecemos o início da comunicação/interação mediada utilizando a enquete que buscava conhecer o produto cultural preferido dos alunos. Esse tipo de interação ou recurso também tem a finalidade de promover o empoderamento dos/as alunos/as que se posicionam como participantes detentores de voz, sem a qual o próprio gênero se perde. O resultado demonstrou que os/as alunos/as preferem filmes e DVDs (seriados ou shows), conforme o gráfico 1. Em parte, esse perfil reflete o fato de que os/as jovens estão mergulhados na cultura global, logo preferem textos multimodais (como os filmes) a textos tradicionais (como o livro impresso).

Gráfico 1: Produtos culturais

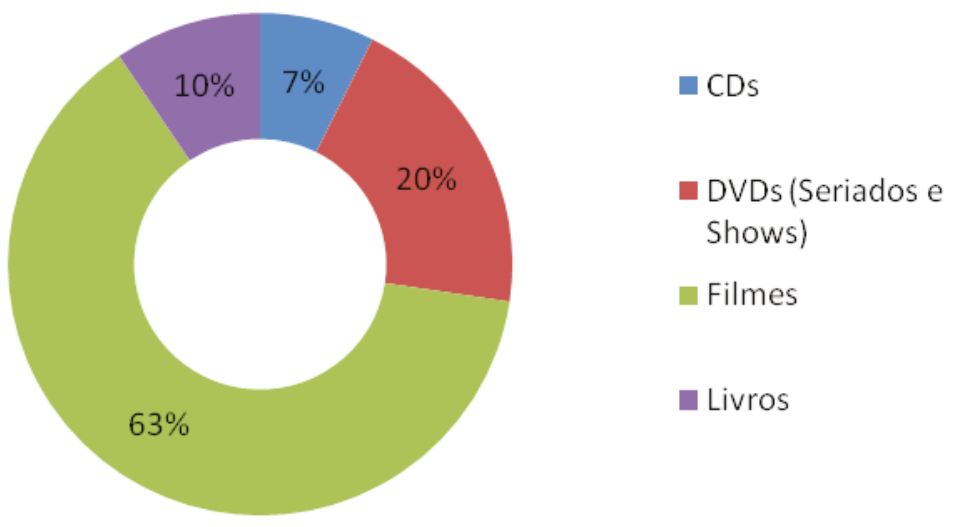

O próximo passo foi o desenvolvimento de resenhas. Os/ as alunos/as, individualmente, deveriam preencher o quadro exploratório (ver anexo l) com uma breve sinopse sobre o produto cultural do seu respectivo grupo, e os aspectos positivos e negativos com as devidas justificativas. Essa atividade foi elaborada com a finalidade de introduzir os/as leitores/as na esfera da apreciação, indispensável ao gênero resenha. 
A atividade individual proporcionaria o amadurecimento de cada um/a em relação à escrita, para, em seguida, os/as alunos/as voltarem a seus grupos para a troca de informações/comentários sobre o produto estudado coletivamente. Em grupo, um novo gênero foi introduzido: ficha técnica (ver anexo 2). Essa nova atividade consistia em preencher o formulário com as informaçôes sobre autor, editora/produtora, quantidade de páginas/minutos, conteúdo/lista de músicas, artistas, diretores, classificação, prêmios, curiosidades, entre outras, para a qual teriam o tempo de uma semana.

Preenchidas as fichas, iniciamos o estudo do gênero propaganda. Em grupo, os/as alunos/as deveriam buscar informações sobre as propagandas, inclusive, estrutura textual, veiculação e produção. Os grupos dedicaram-se à elaboração de uma propaganda em vídeo com a finalidade de divulgar os produtos culturais escolhidos e, principalmente, desenvolver a argumentação oral, sendo obrigatória a atuação de todos/as os/as integrantes.

Pertinente ao processo de elaboração da propaganda, os/as alunos/as foram orientamos sobre a elaboração do gênero roteiro, bem como do planejamento e da direção (definir o local de gravação, figurino, etc.). Para finalização de cada vídeo/propaganda, os grupos estavam livres para trabalhar em conjunto com os/as estudantes de informática ou empresas de editoração de imagens. Cada grupo teria cerca de um mês para concluir essa etapa.

Além disso, criamos um espaço no Flickr para divulgarmos fotos das etapas do projeto, bem como os bastidores das gravações dos vídeos (ver Figura 2). 
Figura 2: Fotos do projeto divulgadas no Flickr
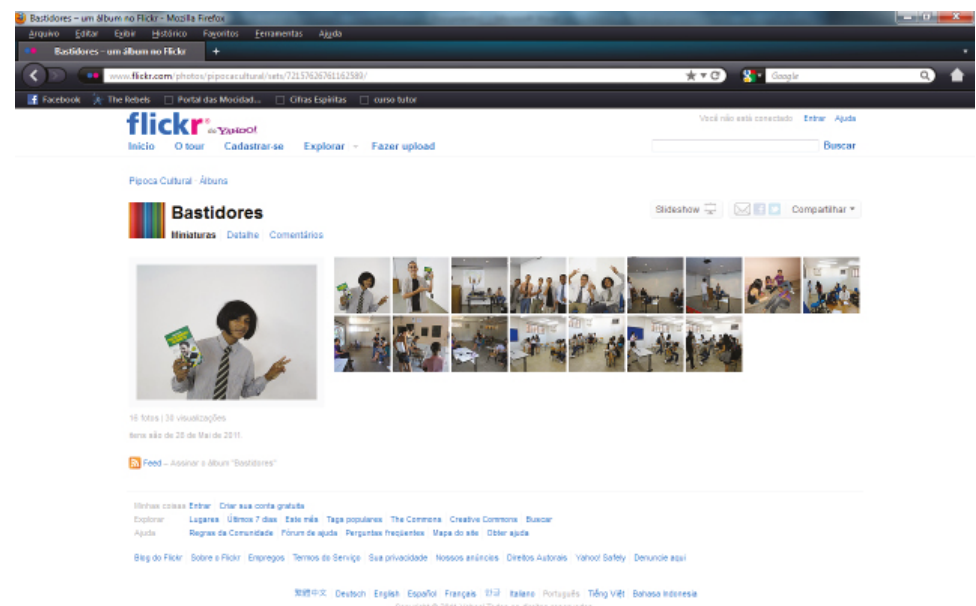

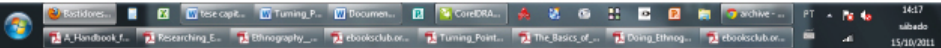

Concomitantemente à preparação dos vídeos, realizamos, em sala de aula, as reescrituras das fichas técnicas, sinopses e resenhas, para serem divulgadas no blog do projeto.

Munido o blog com as informações de cada produto cultural, pedimos aos/as alunos/as que escolhessem outro produto cultural do catálogo oferecido pelo blog. A exploração do blog permitiu aos/as estudantes a crítica sobre o trabalho realizado pelos seus pares. Além disso, estimulou cada um/a a aprofundar suas próprias habilidades, uma vez que o "resultado" de sua escrita estaria cumprindo o papel de produzir comunicação, dentro de uma prática real, em que eles se posicionavam como produtores e consumidores de conhecimento.

Na penúltima etapa, promovemos as exibições das propagandas no Festival de Vídeos Pipoca Cultural, realizado, especificamente, em 30 e 31 de maio. Os critérios estabelecidos para a avaliação dos vídeos foram, principalmente, a expressividade 
(gênero oral) e a argumentação (voltada para o marketing), a adequação ao gênero, além dos recursos técnicos utilizados (ver Figura 3).

Figura 3: Festival de Vídeos Pipoca Cultural

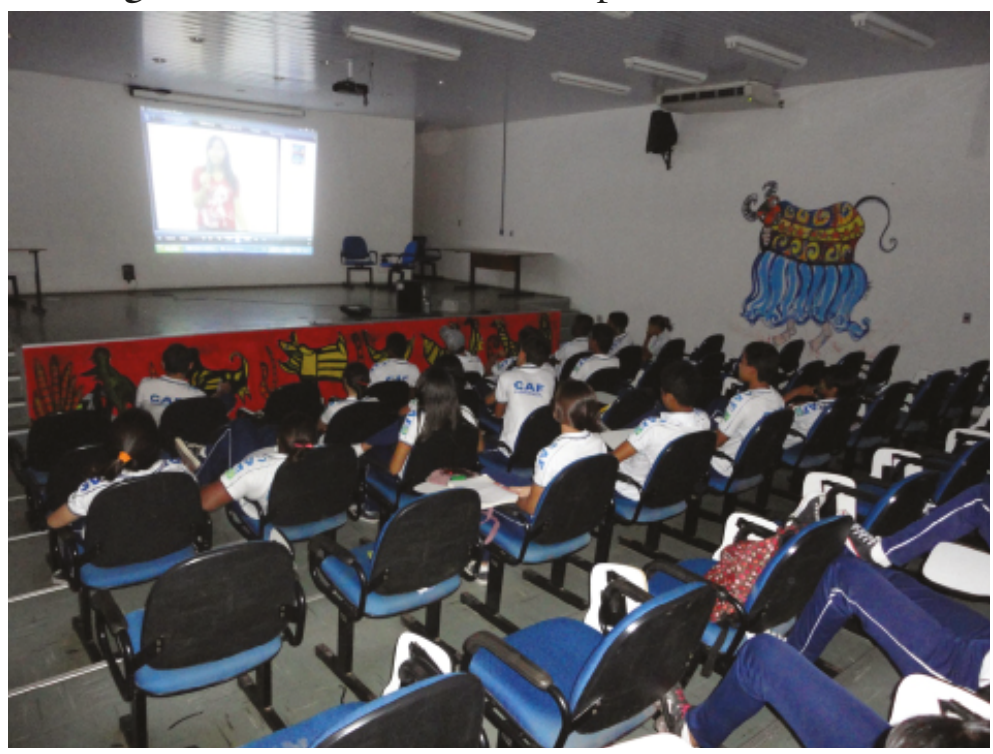

Todos os vídeos produzidos foram expostos em um canal criado no YouTube (ver Figura 4). 
Figura 4: Canal do Pipoca Cultural no YouTube

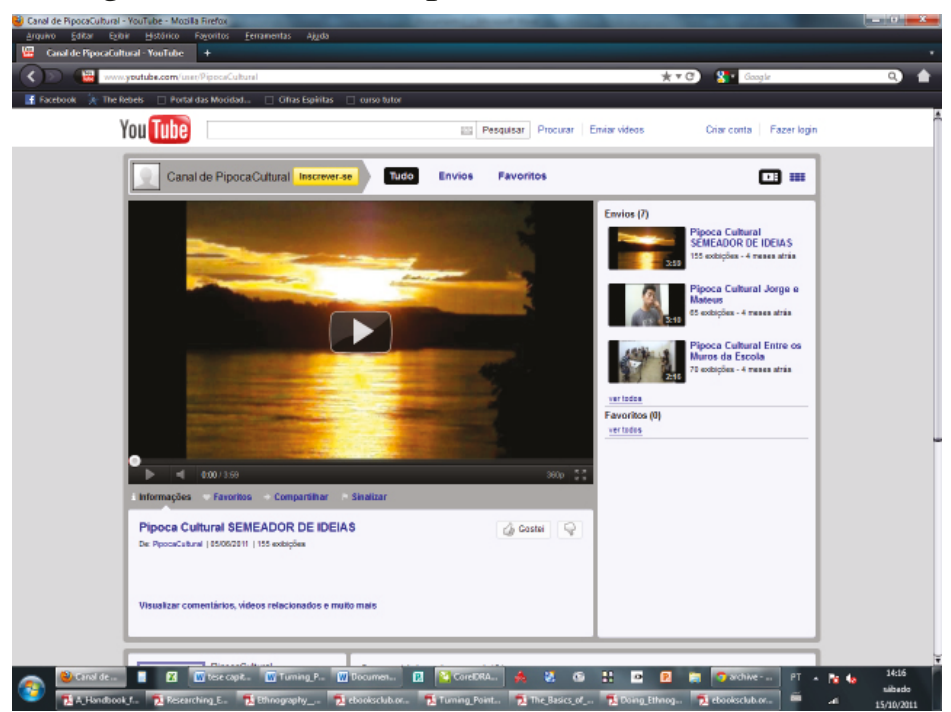

Realizado o festival, cada aluno, individualmente, deveria acessar o blog, escolher um novo produto cultural entre aqueles divulgados, postar um comentário, explicitando e justificando a sua escolha. Nessa etapa, o gênero comentário teve a finalidade de trabalhar a expressividade, conforme textos abaixo:

João disse...

eu João da turma EMTA-1 escolhi o filme AVATAR pelo fato do ótimo grafico e a forma de como o filme foi planejado, no periodo que se esperava um faturamento aconteceu desse mesmo periodo já se ter ultrapassado esse valor.

6 de junho de 2011 11:22

Gustavo disse...

Eu Gustavo, [EMTI-1], escolho o dvd Luan santana 2010 ao vivo no Rio, porque é um ótimo dvd que tem boas músicas e atualmente está fazendo muito sucesso.

6 de junho de 2011 12:15 
José disse...

Eu José EMTI-1.Escolho o filme A origem. Porque eu li a sinopse e vi o vídeo e gostei muito.

7 de junho de 2011 10:27

\section{Luciana disse...}

Eu, Luciana, escolhi o filme A rede social.

Achei bem interessante a sinopse do filme no blog e por isso resolvi escolhê-lo, e também, por contar o surgimento da rede social que mais cresce no mundo, o Facebook.

Luciana, EMTA-1.

8 de junho de 2011 09:22

A última etapa prevista do projeto foi a elaboração de uma nova resenha. Infelizmente, essa etapa não foi realizada em virtude do fechamento do semestre, visto que o tempo demandado para produção, leitura (por parte do professor) e reescritura dos textos extrapolaria o período disponível. Logo, achamos pertinente redimensionarmos o projeto finalizando-o com o gênero avaliação coletiva oral, em que trabalhamos a autoavaliação e a avaliação da atividade, com relatos da experiência e das dificuldades. Destacamos que não obtivemos resultados satisfatórios com a utilização do Twitter, visto que a rede possuía pouca acessibilidade entre os/as alunos/as.

\section{Considerações finais}

O projeto Pipoca Cultural recebeu avaliação satisfatória por parte do nosso público-alvo. Entre os benefícios relatados, estava a capacidade crítica, a melhoria da leitura, e, principalmente, a formação identitária dos/as alunos/as como leitores eficientes. Por esses resultados, pretendemos tornar o projeto uma prática permanente no primeiro semestre de cada ano. De fato, observamos que os produtos culturais e as redes sociais despertaram interesse nos/as alunos/as o que os/as manteve motivados/as durante todo o processo de planejamento, execução, reescrita e apresentação dos trabalhos. 
O envolvimento e a adesão foram relevantes do ponto de vista do ensino-aprendizagem, porque trouxe a compreensão e a percepção de cada etapa e dos diferentes gêneros. Todo o processo foi enriquecido pelas discussões sobre o projeto em sala de aula, chegando as quatro turmas à mesma conclusão de que a leitura não se limita a mera decodificação de um texto escrito, e que textos multimodais (como um filme), por exemplo, se estruturam a partir de diferentes gêneros que os perpassam, como capa e/ou cartaz, falas, imagens e sons que compóem a obra, até os créditos finais. Da mesma forma, compreenderam que a escrita exerce influências no ambiente social, extrapolando a prática escolar. Outra consequência percebida foi o fato de que suas frases, recados e mensagens postadas nas redes sociais são atividades de escrita e leitura que envolvem habilidades específicas, julgamentos e conhecimentos prévios.

Por fim, o significativo interesse e motivação dos alunos revelaram as possibilidades/potencialidades do uso de produtos culturais e das mídias digitais de modo geral no processo ensinoaprendizagem, especialmente a internet e suas ferramentas, instrumentos cada vez mais presentes no cotidiano dos estudantes. Contudo, o desempenho e os depoimentos dos alunos em relação ao projeto foram evidências de que as atividades desenvolvidas no Pipoca Cultural traduzem-se em aprendizagens significativas não somente na perspectiva da língua portuguesa, mas também na perspectiva da formação desses jovens de modo geral.

\section{Referências}

BARTON, David. Literacy: an introduction to the ecology of written language. Oxford, Cambridge: Blackwell Publishers, 2006.

. Literacy practices. In: CULPEPER. Jonathan et al (Org.). English Language: description, variation and context. London: Palgrave Macmillan, 2009, p. 477-486. 
BATISTA Jr., José Ribamar Lopes et al. Práticas de leitura no Ensino Médio Profissionalizante. In: SEMINÁRIO NORTE-NORDESTE DE PESQUISA E INOVAÇÃO, 5, 2010, Maceió. Anais. Maceió: EDIFAL, 2010.

BATISTA Jr., José Ribamar Lopes; SILVA, Francisco das Chagas Rodrigues da. Gêneros textuais, digitais e redes sociais: praticas de leitura e escrita no ensino médio profissionalizante. In: Simpósio Hipertexto e Tecnologias na Educação, 3, 2010, Recife. Anais. Recife: NEHTE, 2010.

BATISTA Jr., José Ribamar Lopes; SILVA, Francisco das Chagas Rodrigues da; LIRA, Luciane Cristina Eneás. Redes sociais e práticas de leitura e escrita no Ensino Médio. Hipertextus Revista Digital, UFPE, n. 6, p. 1-9, 2011.

SILVA, Edna Cristina Muniz da. Gêneros e práticas de letramento no ensino fundamental. 2007. 258f., il. Tese (Doutorado em Linguística) Universidade de Brasília, Brasília, 2007.

XAVIER, Antonio Carlos. Letramento digital: impactos das tecnologias na aprendizagem da Geração Y. Calidoscópio, Unisinos, v. 9, n. 1, p. 3-14, 2011. 


\section{ANEXO 1 - RESENHA}

\section{Produto Cultural:}

\section{Sinopse:}




\section{ANEXO 2 - FICHA TÉCNICA}

\section{Filme:}

\begin{tabular}{|l|l|l|}
\hline \multicolumn{2}{|l|}{ Título Original: } & Gênero: \\
\hline Ano: & País: & Data de estreia: \\
\hline
\end{tabular}

Diretor:

Elenco:

\begin{tabular}{l|l|l}
\hline Cor: & Duração: & Classificação: \\
\hline
\end{tabular}

Sinopse:

Prêmios:

Curiosidades: 